\title{
Comparative Study of Learning Strategies of Bachelor Students in Nursing
}

\author{
Mary Arely López Garrido ${ }^{1}$, José Alberto Hernández Aguilar², \\ Carlos Alberto Ochoa Ortiz ${ }^{3}$, Erika Yunuen Morales Mateos ${ }^{1}$, \\ Carolina González Constantino ${ }^{1}$ \\ ${ }^{1}$ Universidad Juárez Autónoma de Tabasco Cunduacán, Tabasco, Mexico \\ ${ }^{2}$ Universidad Autónoma del Estado de Morelos, Cuernavaca, Morelos, Mexico \\ ${ }^{3}$ Universidad Autónoma de Ciudad Juárez, Ciudad Juárez, Chihuahua, Mexico \\ arely.lopez@ujat.mx, jose_hernandez@uaem.mx, erika.morales@ujat.mx, alberto.ochoa@uacj.mx, \\ carolina.gonzalez@ujat.mx
}

\begin{abstract}
This study aims to graphically represent a comparison between men and women of the results obtained in the EDAOM of students of Nursing Baccalaureate, for this is selected the newly admitted students in the cohorts, 2010, 2011 and 2012 that answered the EDAOM through the institutional system of tutorials, describes the sample using statistical measures of central tendency, a correlation analysis between the subscale of EDAOM and finally the representation in a radial graph of the results obtained in the EDAOM where each axis represents a subscale with the respective value for men and women. It is concluded that there is a need to strengthen the motivational guidelines where both population samples obtained low results.
\end{abstract}

Keywords: Learning strategy, Academic performance, Comparative, Radial graph.

\section{Introduction}

In Mexico the Institutions of Superior Education (IES) have the problem of desertion and lag and as a result student low rate of efficiency terminal, being necessary to increase the performance of the students to reduce the disapproval and the desertion and thereby better results in the indicators of utilization and efficiency terminal. To support the IES the National Association of Universities and Institutions of Higher Education (ANUIES) made the document HIGHER EDUCATION IN THE TWENTY-FIRST CENTURY, within this document is the Program of Integral Development of the students, in which he proposes that the IES implement tutoring programs and integral development with the objective of supporting the students, so that a high portion of them completed their studies in the times scheduled [1], for this reason the IES implemented and operate institutional programs of 
tutorials to help you pull down the desertion, disapproval, academic lag and increasing efficiency terminal [2].

Some IES, as part of the operation of the institutional program of tutorials, to the new students answer the inventory of learning styles and motivational guidance (EDAOM), this consists of a self-assessment that the student makes on their learning strategies [3]. The results obtained reinforce the learning strategies.

Learning strategies are the conscious and intentional activities that guide the actions to be taken to reach certain learning goals [4].

Through the student's learning strategies, the causes of low or high academic achievement can be identified [5], in other words, improving learning outcomes can be achieved by incorporating assessment procedures to identify risks and determining strategies that should be encouraged [3].

We have found some studies that have used data analysis techniques to determine which subjects put at risk of dropping to a student due to failure, this information is useful to the tutor to implement learning strategies that support academic performance [6], or through some psychological test determining academic achievement [7]. Other studies employ grouping techniques to classify learning styles [8] or classification rules to know the relationship between academic and personal factors with academic performance [9].

There have been a number of investigations to determine the relationship between the EDAOM and academic performance, such is the case of the study by Gonzalez, Castaneda and Maytorena [10], in which it is evaluated to 229 degree students with the objective of obtaining a structural model for the diagnosis of self-reported strategies in undergraduate students to explain the school achievement. At the University of Magdalena Colombia conducted a descriptive-correlational study of the learning styles and averages academics, the obtained correlations are not significant in determining that there is no statistically significant relationship between the styles of learning and academic performance [11]. In 2013 another study was conducted to determine the relationship between the learning strategies and the academic performance, the study was conducted with 144 students, concludes that there is no relationship between the learning strategies and performance [12].

The different data analyses were performed using various tools. The descriptive analysis was performed with SPSS Statistics 22, obtaining the correlations between the subscale of EDOAM and the radial graph was used $\mathrm{R}$.

This study aims to graphically represent a comparison of the results obtained from the EDAOM of undergraduate students in nursing, and in this way to know that learning strategies need to be strengthened.

\section{Materials and Proposed Methods}

\subsection{Description of the Data}

The objective of this study is to perform a comparison of the learning strategies employed by the students of the Nursing Baccalaureate belonging to an institution of higher education 
in the southeast of Mexico, a descriptive study was performed, the participants were all newly admitted students belonging to the generational cohorts 2010, 2011 and 2012 so that the sample was not probabilistic or addressed to [13]. This sample was composed in total by 44 students, distributed in the following manner: female gender male $82 \%$ and $18 \%$, between the ages of 18 and 30 years.

\subsection{Inventory of Learning Styles and Motivational Guidance (EDAOM)}

The instrument used was the Inventory of Learning Styles and Motivational Guidance, which allows to identify quickly, the self-evaluations that the students of middle and higher education make of their learning strategies and motivational guidelines to the study. The EDAOM is composed of two sections, used in this study is that of self-reported that measures the self-evaluations of students on the learning strategies and motivational guidelines from the frequency, the difficulty or ease and the quality of the results of the use of these strategies, has 89 Likert-type reagents, corresponding to 4 scales: a) styles for the acquisition of information, b) styles of information retrieval, c)styles of information processing and d) styles of metacognitive self-regulation and meta-motivational, Figure 1 shows the structure of the EDOAM [3]..Below are the strategies that evaluate the EDAOM [12]:

- The Strategies of Acquisition of the information is composed by:

- Selective. Superficial processing strategies of what is being learned. Important information is selected in the most rapid and complete way, to understand it and to use it in new learning. They include, flipping through and quick readings of materials with the aim of finding the most important, underlining to find information quickly, reviewing when the material is difficult to understand.

- Generative. They are strategies of deep processing of the acquired information, it adds a symbolic construction of which is being learned. Some strategies are: Analogies to relate concepts, mental mapping, structuring what is read using synoptic tables.

- The Strategies of Recovery of the information learned, allow to: pre-activate, reactivate and keep activated the information to be able to be used later. Some of these strategies are: rereading, generating questions to evaluate what is understood, remembering an image.

- Faced with different academic tasks

- During exams

- The Processing Strategies are related to structuring the information learned and to reason or criticize what has been learned. Some of these strategies are: grouping of concepts into categories, relating ideas together, and structuring knowledge through conceptual maps.

- Convergent style. Reproduce the information to be learned.

- Divergent style. Create innovative productions and think critically about what has been learned. 
- The Metacognitive and Meta motivational Self-Regulation Strategies include activities that allow the student to evaluate, plan, and regulate whether or not he or she has met the learning goals:

- Efficiency perceived

- Internal Contingency

- Perceived autonomy

- Orientation to external approval

- Learning Task Strategies

- Orientation to the task itself

- Orientation to achievement of goals

- Strategy of Learning Materials, as to their usefulness to provide efficient learning.

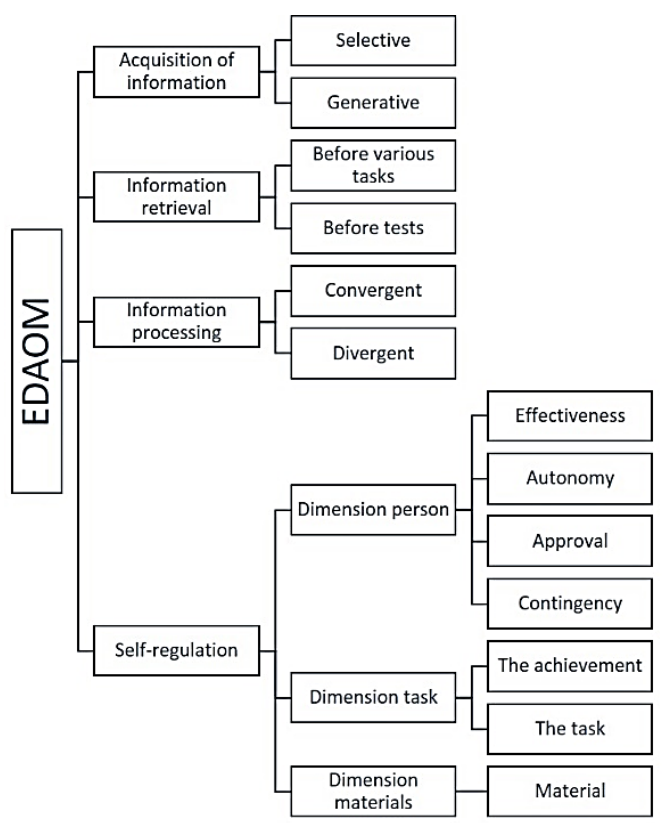

Fig. 1. Structure of the EDAOM.

\subsection{Data Analysis}

A descriptive analysis was applied to the data for the sample and that same applied a correlational analysis and understanding of the relationship between the subscales of EDAOM.

Finally was represented in a graph radial for a comparison of the averages of the assessment of the EDAOM between men and women. 
In the descriptive analysis were applied calculations to the sample of this study, corresponding to the minimum and maximum values, as well as the central tendency statistics: median and mean. With a sample of 44 students of the Degree in Nursing, the results obtained are shown in Table 1, noting that the generative subscales, disaster recovery tests, convergent, contingency, guidance to the achievement, and material have an average greater than or equal to 76(minimum score to get a good result of the EDAOM), the minimum value what have the subscales autonomy and approval. The subscale retrieval of information before tests has a mean of 81.55 and Approval has the lowest score at 42.55.

In the sample are recorded a total of eight men and a total of 36 women, whose percentage values correspond to 18 and 82 respectively.

Table 1. Descriptive statistical sample of students of degree in Nursing.

\begin{tabular}{llrrrrr}
\hline \multicolumn{1}{c}{ Scales } & Subscales & Media & Medium & $\begin{array}{l}\text { Diversion } \\
\text { Standard }\end{array}$ & Min & Max \\
\hline $\begin{array}{l}\text { Acquisition } \\
\text { of the }\end{array}$ & Selective & 68.59 & 69.00 & 12.006 & 37 & 91 \\
$\begin{array}{l}\text { Information } \\
\text { Retrieval of }\end{array}$ & Generative & 78.95 & 78.50 & 9,970 & 51 & 100 \\
$\begin{array}{l}\text { Information } \\
\text { various tasks }\end{array}$ & 71.59 & 70.00 & 8.241 & 47 & 90 \\
Information & Before Tests & 81.55 & 83.00 & 11.619 & 50 & 100 \\
processing & Convergent & 76.73 & 77.00 & 13.407 & 46 & 100 \\
Motivational & Divergent & 72.77 & 71.00 & 14.595 & 31 & 97 \\
Guidance & Effectivenes & 50.86 & 51.00 & 10.973 & 23 & 71 \\
& s & & & & & \\
& Contingency & 79.27 & 79.00 & 7.456 & 64 & 94 \\
& Autonomy & 50.23 & 51.50 & 12.077 & 6 & 71 \\
& Approval & 42.55 & 41.00 & 16.936 & 14 & 86 \\
& The & 80.84 & 81.50 & 12.844 & 34 & 100 \\
& achievement & & & & & \\
& The task & 72.80 & 71.00 & 10.529 & 49 & 94 \\
& Material & 78.59 & 80.00 & 11.639 & 57 & 100 \\
& & & & & & \\
\hline
\end{tabular}

\section{Results}

\subsection{Correlational Analysis}

Correlation analysis consists of analyzing data from a sample to know the degree of association or relationship between two or more variables in a population [14]. For known if there are associations between the subscales (Selective, Generative, Information retrieval before tasks, Retrieval of information before exams, Convergent, Divergent, Efficacy, 
Contingency, Autonomy, Approval, Homework Orientation, Orientation to goal achievement and materials ) of the EDAOM, a correlation analysis was performed between the variables, as shown in Figure 2, the most significant relationships are between: generative subscales and information retrieval during the tests with a level of 0.84 , which allows determining that the style of information acquisition is generative in which students use critical thinking to build new knowledge thus facilitating the retrieval of information learned during exams.

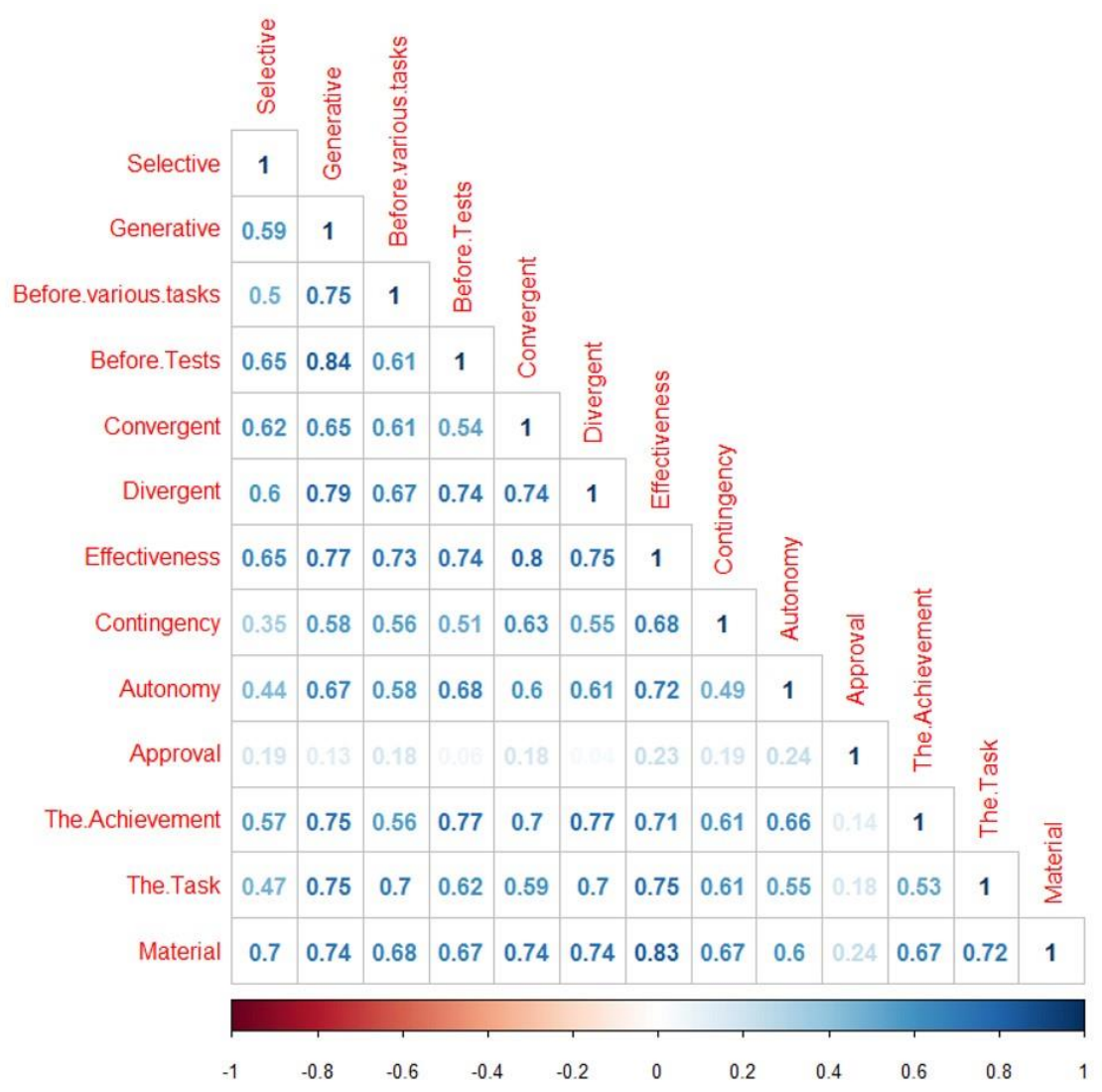

Fig. 2. Correlation of subscale of EDOAM of undergraduate students in Nursing, Source: (Selfrealization, 2015).

The relationship between the convergent and perceived efficacy subscales has a level of 0.8 , the student considers that it obtains effective results when using the style of processing of the convergent information which consists of reproducing the information learned. 
The relationship between the perceived efficacy subscales and the material correlation level is 0.83 , the student considers that it has obtained effective results when searching for and adding new material in addition to the one indicated and provided by the teacher.

\subsection{Radial Representation}

There are studies in which the principal components are analyzed in order to reduce the dimensionality of the data and can be represented and visualized in a more simple way [15]. The radial representation has become an effective option in the support of visualizations of high dimensionality and with large volumes of data, with increased scalability and with a better use of available space [16]. In a radar chart you can make a representation of the differences between the results obtained and the results ideals [17]. Presents from the origin of coordinates the position reached by the different variables of a study, this way can determine how dispersed or concentrated the variables are found [18].

Viewing the comparison of the results obtained from the assessment of the EDAOM of students on the Degree in Nursing is shown in Figure 3 via a radial graph. In this graph is plotted in each axis the result of each subscale of the EDAOM of men, women and the ideal minimum value. Table 2 shows the guide to interpret the results obtained from the EDAOM.

Table 2. Interpretation of EDAOM Guide.

\begin{tabular}{ll}
\hline \multicolumn{1}{c}{ Percentages } & Interpretation \\
\hline $100-76$ & Good development of strategies. \\
$75-56$ & $\begin{array}{l}\text { Suggested to strengthen the learning strategies or } \\
\text { motivational guidance. It is a regular result does not } \\
\text { represent a critical failure. } \\
\text { Notes the need to train learning strategies or } \\
\text { motivational guidance. }\end{array}$ \\
\hline
\end{tabular}

Figure 3 shows the results obtained by the students of the Bachelor in nursing which is compared by men and women and in addition the minimum percentage that indicates that there is a good development of learning strategies.

On the basis of this representation shown below is the description of the results obtained by both men and women and the result required minimum that indicates a good development of strategies:

In the subscale Selective both men and women obtained a result regulate, which indicates that requires strengthening these strategies.

In the subscale disaster recovery tasks indicate that although women obtained a better result those women, both require reinforcing these strategies.

With regard to the processing women get a converged result regulate, requiring strengthening these strategies.

In regard to the subscales Effectiveness, autonomy and approval both obtain a low result, i8ndicando that work is needed in the strengthening of these strategies. 
Then described the results toward the comparison between men and women: shows that women employ more the strategy of acquisition of the selective information that is performed by selecting information fast readings more important, understanding literally what they are reading and use this knowledge when necessary in new programming.

In the subscale of information retrieval, women use strategies that allow you to retrieve the knowledge about the different academic tasks unlike men who employ more recovery strategies of the information during the tests.

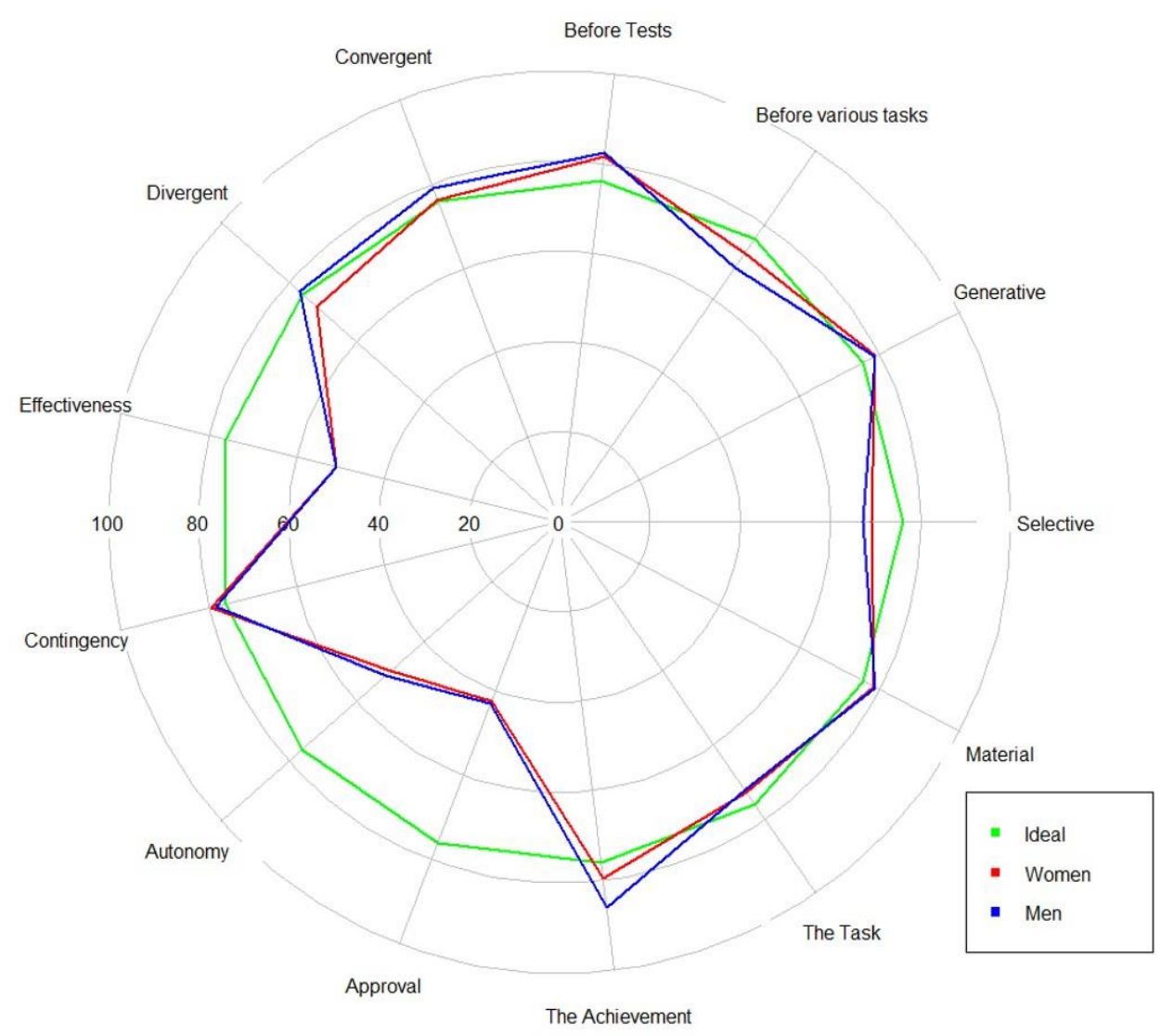

Fig. 3. Radial representation of the subscale of EDAOM of students of degree in Nursing (Source: Self-realization, 2016).

For the scale of information processing the man have a better outcome than women, it is noted that the men were a better result in the converged subscale that is used strategies that allow you to reproduce the information learned; likewise in the subscale divergent its result 
is better than that of women indicating that employ strategies that allow you to create and think critically about what they have learned

In regard to the perceived autonomy to achieve their learning men obtained a better result than women.

With regard to the orientation to the achievement of goals that indicates the motivation to learn, men obtained a good result, better than women.

\section{Conclusions and Future Work}

Currently due to the need to improve and maintain the quality indicator efficiency terminal, which is affected by the lag caused by the disapproval, further studies are needed to know the strategies employed by the students and in this way the academic administration make the best decisions to strengthen if necessary the learning strategies. It is important that elements be used to visualize the results obtained. The implementation of the radial graph in this study allowed to show in a simple way the values obtained in the different subscales and to display the results of men and women.

Among the future work has considered the use of other graphs that let you display in a simple way the Analysis of Multivariable Data.

\section{References}

1. Romo, A.: La incorporación de los programas de tutorías en las instituciones de educación superior. Asociación Nacional de Universidades e Instituciones de Educación Superior (2004)

2. Universidad Juárez Autónoma de Tabasco: Programa Institucional de Tutorías (2003)

3. Castañeda, S.: Educación, aprendizaje y cognición. Teoría en la práctica. El Manual Moderno S.A. de C.V, pp. 277-298 (2004)

4. Valle, A., Barca, A., González, R., Núñez, J. C.: Las estrategias de aprendizaje. Revisión teórica y conceptual. Revista latinoamericana de Psicología, 31(3), pp. 425-461 (1999)

5. Beltrán, J. A.: Estrategias de aprendizaje. Revista de Educación, 332, pp. 55-73 (2003)

6. Quintana, M., Trinidad, J. C., Morales, S. J., Landassuri, V. M.: Análisis Comparativo de Algoritmos de Minería de Datos para Predecir la Deserción Escolar. Research in Computing Science 67, pp. 51-61 (2013)

7. Quintana, M., Hernández, J. E.: Análisis de la Influencia de las Inteligencias Múltiples en el Desempeño Académico Aplicando Técnicas de Minería de Datos. Research in Computing Science 67, pp. 51-61 (2013)

8. Gudino-Penaloza, F., González-Mendoza, M., Mora-Vargas, J.: Uso de técnicas de agrupamiento en la clasificación de estilos de aprendizaje. Research in Computing Science 95, pp. 135-146 (2015)

9. González, S. B., Figueroa, J.: Discovering Relationships among Personal and Academic Factors with Academic Performance using Association Rules. Research in Computing Science 118, pp. 9-17 (2016) 
Mary Arely López Garrido, José Alberto Hernández Aguilar, Carlos Alberto Ochoa Ortiz, et al.

10. González, D., Castañeda, S., Maytorena, M.: Estilos de aprendizaje y aprovechamiento en ingresantes universitarios. Revista de Psicología de la PUCP (2000)

11. Barboza, C., Lara, R., Palmezano, A.: Estilos de aprendizaje y rendimiento académico en estudiantes universitarios. (2008)

12. Niño, M.: La Relación Estilos de Aprendizaje y Rendimiento Académico en Alumnos de una Facultad de la UANL. (2013)

13. Hernández, R., Fernández-Collado, C., Baptista, P.: Metodología de la Investigación. Mc Graw Hill (2006)

14. Nieves, A., Domínguez, F.: Probabilidad y Estadística para Ingeniería. McGraw Hill (2009)

15. Manufacturing Terms: Radar Gráfico. (2016)

16. Alvarado, J.: Visualización multidimensional, nuevas técnicas de exploración de datos y representación de información. Revista Memorias, Vol. 8, No. 14, pp. $72-84$ (2010)

17. Martínez, L., Pérez, M.: Análisis de Estrategias de Gestión: aplicaciones polivalentes del gráfico radial. (2011) 